\title{
The Art of Zen informed consent
}

$\mathrm{I}_{\mathrm{p}}^{\mathrm{n}}$ nformed consent is the state of understanding between physician and patient, occurring after a full discussion of the diagnosis, possible treatments and possible results of not having treatment. The signed consent form is a record of agreement that the consent has occurred. Various interpretations say that the consent has to cover every complication, even if rare, if that complication could result in a serious problem.

So far so good - consent seems to be the natural evolution to a more modern state of self-determination and objective decision-making. It is rational, objective and cool. It liberates and empowers a person to make their own decision and assess the situation because the patient is the one who will suffer the consequences of not being informed and making a poor decision when a better decision is available. It puts the patient in the driver's seat when it comes to making a decision that is his/hers alone to make. And, as expected, the requirement for thoroughness of consent is greatest in the elective situation and least in an emergency.

The problem with informed consent is that it is impossible to actually do according to the standard outlined above. To be fair, it is impossible to do on all patients all the time. Ask anyone who has tried. Here is why:

- Informed consent is the ultimate rational decision. If you have been a surgical patient you do not necessarily want this. You do want your surgeon to give you the bottom line. You want him/her to give you what he/she would do in your circumstance and you want him/her to explain things in a way that you can understand why he/she would do it. You want him/her to be convinced that it is the right thing to do, with enough conviction that he/she convinces you that he/she will stand behind the decision and can back it up. You also want to be convinced that if the right course of action is no surgery but something else - perhaps watchful waiting - that he/she is convinced on balance that this is right for you. You need to know whether you need to decide immediately or have the luxury of time. You need to understand the likely effect of delay. These decisions can be more important that the actual surgery. You need to hear one course of action, the best course, and maybe a second choice. What you do not want is a whole list of possibilities with pros and cons. Without hearing the best choice, you might as well be your own doctor or in a restaurant looking at the menu.

- Consent is a form of transference. Listing all complications is a way of saying, "if anything goes wrong, you (the patient) take the blame because you decided to have surgery'. Patients do not want this. They need the surgeon to take responsibility for whatever they can control. Trust is necessary for surgery to take place, for without trust, the surgical experience can become a nightmare. Informed consent is based on a theory that, stated simply, is 'trust through full disclosure'. This test would be satifying a legal requirement, however, that is not necessarily how trust occurs, but perhaps how lawyers think trust should be engendered, viewed only through the prism of individual rights.

- Consent is highly language-dependent. The trouble with that is that there are many levels of understanding, and not just vocabulary. The words used describe concepts such as risk, chance, incidence and percentages. In a multiracial society, it is difficult to be sure of the translative ability of those who interpret these concepts because they are much more than words, they are complex ideas.

- A passed informed consent 'test' is not an indication for surgery, but it easy to think that it is. After all, you could easily say, "the patient wanted to go ahead with surgery, after I explained everything in detail". This test would be satisfying only a legal requirement and a cultural objective of self-determination. It is not the indication for surgery because the patient may have chosen a course of action unlikely to result in achieving his/her goal. The surgeon has to be resolute in assessing the goal, describe the best means of achieving it, and decline surgery if the patient rejects his/her best advice. The argument that 'somebody else will do it' is not an indication for surgery.

So much for the problems; consent has good objectives and it can work for patients in a positive manner.

- We can discuss potential problems from the point of view of controlling them in advance of surgery. To those who are healthy, we can say, "you are in good shape to undergo this operation, and your risk level is low". To those who are obese, diabetic, hypertensive, 
or have heart disease, addictions or a history of deep venous thrombosis, we can say, "your risks are higher, but you can lower them by following certain measures". Patients who refuse to attempt to lower their risk factors for elective surgery should have their surgery postponed. It is not just the patient who takes the risk. Being in a rush to do something elective or being in denial of important health factors is a bad sign.

Consent is important, but it is necessary to understand it, and nobody understands it like a physician who has tried to do it. It is crucial to see it for what it is, and what it is not because only then will we be able to debate with lawyers when they attempt to use it as a legal argument and construct situations that do not exist in real life. Consent has a certain 'Zen', because everyone has heard the word, but few know what it is.

It is time to put art and Zen back into consent where they belong.

John R Taylor 